\title{
Internal transvenous low energy cardioversion for the treatment of cardiac arrhythmias
}

\author{
ANTHONY W NATHAN, RODNEY S BEXTON,^ ROWORTH A J SPURRELL, \\ A JOHN CAMM \\ From the Department of Cardiology, St Bartholomew's Hospital, London
}

SUMMARY Low energy endocardial cardioversion was attempted in 23 patients with 30 arrhythmias, of whom only four were receiving additional drug treatment. Four had atrial flutter, five atrial fibrillation, three intra-atrioventricular nodal tachycardia, two atrioventricular re-entrant tachycardia, 13 ventricular tachycardia, and three ventricular fibrillation. A pacing lead with special large surface area electrodes - the active electrode positioned either in the right atrium or in the right ventricular apex and the indifferent electrode in the right atrium, superior vena cava, or inferior vena cava - was used together with a low energy defibrillator. A total of 114 shocks was delivered, 26 of which were atrial. One episode of atrial flutter was terminated, but atrial fibrillation and atrioventricular nodal tachycardia were not terminated in any of the patients. Both patients with atrioventricular tachycardia were successfully treated, as were eight of the patients with ventricular tachycardia. Atrial fibrillation was produced in three patients and non-sustained ventricular tachycardia in one, ventricular tachycardia was accelerated in two, and ventricular fibrillation induced in five. Fourteen patients experienced severe discomfort and seven mild or moderate discomfort, and only one found the procedure painless. One patient was anaesthetised throughout the procedure.

Low energy endocardial cardioversion is not universally successful even at the highest energies tolerable, and with the present electrode and pulse waveforms some patients may suffer considerable discomfort.

Direct current external cardioversion is an effective method for treating most tachyarrhythmias. Conventionally, relatively large energies of $5-400 \mathrm{~J}^{1}$ are delivered through large paddle electrodes placed either on the chest wall or directly on to the heart if used during open chest surgery. Mirowski and his colleagues introduced the concept of an implantable defibrillator in 1970, initially using a pacing lead with an active endocardial electrode within the right ventricle, the indifferent pole being either a remote subcutaneous plate electrode or an electrode in the superior vena cava. ${ }^{2}$ Subsequent clinical work has made use of an active epicardial patch electrode with an indifferent

Requests for reprints to Dr A W Nathan, Department of Cardiology, St Bartholomew's Hospital, West Smithfield, London EC1A 7BE.

*Present address: Department of Cardiology, Freeman Hospital, Newcastle upon Tyne.

Accepted for publication 22 May 1984 electrode in the superior vena cava. ${ }^{34}$ This system has been used to treat both ventricular fibrillation and tachycardia using energies of 25-30 J.4-6 In 1981, Jackman and Zipes reported cardioversion of ventricular tachycardia in the dog using very low energy discharges of 8-1000 mJ delivered through a pacing lead. ${ }^{7}$ They later confirmed and expanded their findings using energies ranging from $0.5-2500 \mathrm{~mJ} .^{8}$ Zipes et al have recently used a similar technique in conscious man. ${ }^{9}$

To evaluate the effectiveness, safety, and patient tolerance of low energy endocardial cardioversion (microshock), a group of patients with a wide variety of arrhythmias was studied.

\section{Patients and methods}

Twenty three patients (18 men and five women, aged 22-70 (mean 48) years) were treated for a total of 30 arrhythmias. Table 1 summarises the patient data. 
Table 1 Patient data

\begin{tabular}{|c|c|c|c|c|c|c|c|}
\hline Case No & $\begin{array}{l}\text { Age (yr) } \\
\text { and sex }\end{array}$ & Diagnosis & Mode of induction & Drugs & Route of insertion & $\begin{array}{l}\text { Tachycardia } \\
\text { cycle length (ms) }\end{array}$ & No of studies \\
\hline $\begin{array}{l}1 \\
2 \\
3 \\
4 \\
5 \\
6 \\
7 \\
8 \\
9 \\
10 \\
11 \\
12 \\
13 \\
14 \\
15 \\
16 \\
17 \\
18 \\
19 \\
20\end{array}$ & $\begin{array}{l}70 M \\
36 M \\
69 M \\
26 M \\
61 \mathrm{~F} \\
22 \mathrm{M} \\
50 \mathrm{~F} \\
60 \mathrm{M} \\
53 \mathrm{~F} \\
24 \mathrm{M} \\
47 \mathrm{M} \\
53 \mathrm{M} \\
54 \mathrm{M} \\
23 \mathrm{M} \\
35 \mathrm{~F} \\
35 \mathrm{~F} \\
62 \mathrm{M} \\
58 \mathrm{M} \\
47 \mathrm{M} \\
66 \mathrm{M}\end{array}$ & $\begin{array}{l}\text { AFl } \\
\text { VT } \\
\text { AF } \\
\text { AFl/AF } \\
\text { AFl/AF } \\
\text { AVRT/AFl } \\
\text { AVNRT/AF } \\
\text { VT } \\
\text { AVNRT } \\
\text { AVRT } \\
\text { VT } \\
\text { VT } \\
\text { VT } \\
\text { VT } \\
\text { AVNRT } \\
\text { AF } \\
\text { VT/VF } \\
\text { VT } \\
\text { VT } \\
\text { VT/VF }\end{array}$ & $\begin{array}{l}\text { Spontaneous } \\
\text { PES } \\
\text { Spontaneous } \\
\text { PES/spontaneous } \\
\text { PES/spontaneous } \\
\text { PES } \\
\text { PES/microshock } \\
\text { PES } \\
\text { PES } \\
\text { PES · } \\
\text { PES } \\
\text { Spontaneous } \\
\text { PES } \\
\text { PES } \\
\text { PES } \\
\text { PES } \\
\text { Spontaneous/pacing } \\
\text { Spontaneous } \\
\text { Spontaneous } \\
\text { Spontaneous/ } \\
\text { microshock }\end{array}$ & Amiodarone & $\begin{array}{l}\text { Subclavian } \\
\text { Femoral } \\
\text { Subclavian } \\
\text { Subclavian } \\
\text { Subclavian } \\
\text { Femoral } \\
\text { Subclavian } \\
\text { Subclavian } \\
\text { Femoral } \\
\text { Femoral } \\
\text { Femoral } \\
\text { Femoral } \\
\text { Femoral } \\
\text { Femoral } \\
\text { Femoral } \\
\text { Femoral } \\
\text { Subclavian } \\
\text { Subclavian } \\
\text { Subclavian } \\
\text { Subclavian }\end{array}$ & $\begin{array}{l}210 \\
310 \\
550^{\star} \\
195 / 395^{\star} \\
200 / 420^{\star} \\
280 / 185 \\
240 / 340^{\star} \\
380 \\
510 \\
320 \\
335 \\
355 \\
340 \\
255 \\
330 \\
200^{\star} \\
400 / \text { NA } \\
400 \\
400 \\
355 / \text { NA }\end{array}$ & $\begin{array}{l}1 \\
1 \\
1 \\
1 \\
1 \\
1 \\
1 \\
1 \\
1 \\
1 \\
1 \\
1 \\
1 \\
1 \\
1 \\
1 \\
1 \\
1 \\
3 \\
2 \\
1 \\
1\end{array}$ \\
\hline $\begin{array}{l}21 \\
22 \\
23\end{array}$ & $\begin{array}{l}44 M \\
61 M \\
57 M\end{array}$ & $\begin{array}{l}\mathrm{VT} \\
\mathrm{VT} / \mathrm{VF} \\
\mathrm{VT}\end{array}$ & $\begin{array}{l}\text { PES } \\
\text { PES/microshock } \\
\text { PES }\end{array}$ & Varioust & $\begin{array}{l}\text { Subclavian } \\
\text { Subclavian } \\
\text { Subclavian }\end{array}$ & $\begin{array}{l}215-320 \\
265-300 / \mathrm{NA} \\
400\end{array}$ & $\begin{array}{l}5 \\
1 \\
1\end{array}$ \\
\hline
\end{tabular}

*Ventricular cycle length.

tOn one occasion each: amiodarone, disopyramide, flecainide, procainamide, sotalol.

AF, atrial fibrillation; AFl, atrial flutter; AVNRT, atrioventricular nodal re-entrant tachycardia; AVRT, atrioventricular re-entrant tachycardia; VF, ventricular fibrillation; VT, ventricular tachycardia; NA, not applicable; PES, programmed electrical stimulation.

Four patients had atrial flutter, five atrial fibrillation, three atrioventricular nodal re-entrant tachycardia with functional duality of $\mathrm{AH}$ conduction, two atrioventricular re-entrant tachycardia using direct atrioventricular accessory pathways, 13 ventricular tachycardia, and three ventricular fibrillation. Only four patients were receiving antiarrhythmic medication.

\section{ELECTRODES AND DEFIBRILLATOR}

A temporary pacing lead (Medtronic 6880, Medronic Inc, Minneapolis, USA), originally designed for the treatment of ventricular arrhythmias, was used. This is $100 \mathrm{~cm}$ long and has two pairs of stainless steel electrodes which may be used for pacing as well as for cardioversion. The two poles of each pair are separated by $5 \mathrm{~mm}$ and the two pairs are $100 \mathrm{~mm}$ apart $(150 \mathrm{~mm}$ in the electrode used in case 14). Each electrode has a surface area of $125 \mathrm{~mm}^{2}$, and thus the total area of each pole is $250 \mathrm{~mm}^{2}$ when the lead is used for cardioversion compared with $8-10 \mathrm{~mm}^{2}$ for a conventional pacing electrode. The two distal electrodes each have separate conductor coils terminating in separate connector pins, but the two proximal electrodes are interconnected and have a common conductor coil and connector pin. Each coil has a resistance of less than $15 \mathrm{ohms}$. The distal pair may be used for bipolar pacing but must be connected in parallel when used for cardioversion. A central stylet is used to stiffen and manipulate the lead in a similar manner to that used for placing a typical permanent pacing lead.

Two different defibrillators were used. In 14 patients (cases 1-14) a conventional direct current, surface $\mathbf{R}$ wave synchronous defibrillator was used, which generated a damped sinusoidal (Lown) waveform. This, together with a matched resistive attenuator at a typical load of $100 \mathrm{ohms}$ provided attenuation of $60: 1$. To measure the precise voltage and current delivered, output waveforms were recorded on an $x-y$ plotter using a specially constructed isolated amplifier and a transient recorder. The actual energy delivered was then computed to provide a check on the performance of the attenuator.

In nine patients (cases 15-23) a purpose built device was used (Medtronic 2342). This battery powered unit was capable of delivering a truncated exponential waveform (63\% tilt), $5.5 \mathrm{~ms}$ in duration, at energy levels ranging from 10 to $5000 \mathrm{~mJ}$. This functions in asynchronous (selected for atrial stimulation for atrial fibrillation and ventricular fibrillation) or synchronous mode (used for all other arrhythmias). Sensing was from the distal pair of electrodes on the lead and was variable between $0.5-10 \mathrm{mV}$ (to a $15 \mathrm{~ms}$ sine $^{2}$ waveform). The sensing refractory period was 200 ms.

\section{PROTOCOL}

Patients were studied either in the electrophysiological laboratory or in the coronary care unit. The principal method of arrhythmia induction was program- 
med stimulation during electrophysiological study in 16 patients, but the primary arrhythmias in seven patients were spontaneous. Before cardioversion standard methods of pacing (single and double scanning extrastimuli and rapid burst pacing at cycle lengths of between 400 and $215 \mathrm{~ms}$ for between 2 and $20 \mathrm{~s}$ ) were used to attempt termination in order to provide comparative data (except in patients with atrial or ventricular fibrillation).

The pacing lead was introduced through a $10.5 \mathrm{~F}$ gauge split sheath introducer into a subclavian vein in 13 patients and into a femoral vein in 10 . Atrial microshock with the distal electrode on the atrial septum (and also on the lateral right atrial wall in case 1) was attempted in all but one of the patients with atrial or junctional arrhythmias, and ventricular microshock with the distal electrode in the right ventricular apex was used only if atrial shocks were ineffective or intolerable. In the patients with ventricular arrhythmias only ventricular shocks were used. Before cardioversion, a large pacing pulse $(10 \mathrm{~V}, 5 \mathrm{~ms})$ was passed between the proximal and distal pairs of electrodes to check that there was no overt diaphragmatic or phrenic nerve stimulation. An energy of between 3.4 and 1000 (mean 96) $\mathrm{mJ}$ was used for the first attempt at internal countershock, and the energy was increased until success was achieved, maximum output had been used, or until the pain from the shocks became intolerable.

Continuous recordings of electrocardiograms and when necessary of intracardiac signals were made during all interventions at a paper speed of 25 or 100 $\mathrm{mm} / \mathrm{s}$. After the procedure patients were asked to describe any discomfort that they had experienced during the procedure and to grade it as absent, mild, moderate, or severe. No sedation was used in 19 patients, but intravenous diazepam was given to two patients (cases 1 and 3). A general anaesthetic was given to two patients (cases 4 and 16) in order to perform conventional external cardioversion, and before external cardioversion internal microshocks of $740-5000 \mathrm{~mJ}$ were given unsuccessfully.

\section{Results}

A total of 26 shocks (3.4-5000 (mean 502) mJ) was

Table 2 Individual patient results

\begin{tabular}{|c|c|c|c|c|c|c|c|c|c|c|c|}
\hline \multirow{3}{*}{$\begin{array}{l}\text { Case } \\
\text { No }\end{array}$} & \multirow[t]{3}{*}{ Diagnosis } & \multicolumn{4}{|c|}{ No of microshocks } & \multicolumn{2}{|c|}{ Maximum encrgy (mf) } & \multirow[t]{3}{*}{ Pain } & \multicolumn{2}{|c|}{ Arrhythmogenic effects } & \multirow[t]{3}{*}{ Pacing } \\
\hline & & \multicolumn{2}{|c|}{ Atrial } & \multicolumn{2}{|c|}{ Ventricular } & \multirow[t]{2}{*}{ Atrial } & \multirow[t]{2}{*}{ Ventricular } & & \multirow[t]{2}{*}{ Site } & \multirow[t]{2}{*}{ Effect } & \\
\hline & & $F$ & $S$ & $F$ & $S$ & & & & & & \\
\hline 1 & $\mathrm{AFl}$ & 10 & 0 & - & - & 1430 & - & ++ & - & & F \\
\hline 2 & VT & - & - & 0 & 1 & - & 200 & + & - & & $\hat{S}$ \\
\hline 3 & AF & 3 & 0 & 2 & 0 & 1390 & 1300 & ++ & - & & NA \\
\hline 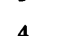 & $\mathrm{AFl}$ & 1 & 0 & - & - & 50 & - & +++ & - & & $\mathbf{F}$ \\
\hline 4 & $\mathrm{AF}$ & - & - & 3 & 0 & - & 3800 & +++ & - & & NA \\
\hline & AFl & 1 & 0 & - & - & 4 & - & $+t+$ & - & & $\mathbf{F}$ \\
\hline 5 & AF & - & - & 3 & 0 & - & 292 & +++ & - & & NA \\
\hline 6 & $\left\{\begin{array}{l}\text { AVRT } \\
\text { AFl }\end{array}\right.$ & 0 & 2 & 0 & 3 & $4 \cdot 8$ & 18 & +++ & - & & $\mathrm{S}$ \\
\hline & AFl & 2 & 0 & 2 & 1 & 94 & 198 & +++ & A shock & AF & $\mathbf{F}$ \\
\hline 7 & $\left\{\begin{array}{l}\text { AVNRT } \\
\text { AF }\end{array}\right.$ & 1 & 0 & 2 & 0 & 17 & 83 & +++ & V shock & AF & $\mathrm{S}$ \\
\hline 8 & VT & - & - & 1 & 0 & - & 170 & +++ & V shock & VT & NA \\
\hline 9 & AVNRT & $\overline{1}$ & $\overline{0}$ & & 1 & $\overline{17}$ & 150 & +++ & - & & S \\
\hline 10 & AVRT & 0 & 3 & & 0 & $\begin{array}{l}17 \\
20\end{array}$ & 200 & $0^{+t}$ & - & & $\mathbf{S}$ \\
\hline 11 & VT & - & - & 2 & 1 & - & 250 & +++ & - & & $\mathrm{F}^{\star}$ \\
\hline 12 & VT & - & - & 2 & 0 & - & 500 & +++ & - & & $\mathbf{F}$ \\
\hline 13 & VT & - & - & 3 & 1 & - & 6700 & ++ & V shock & Faster VT & $\mathrm{S}$ \\
\hline 14 & VT & - & - & 1 & 0 & - & 150 & +++ & V shock & VF & $\mathbf{S}$ \\
\hline 15 & AVNRT & - & - & 4 & 0 & - & 500 & +++ & - & & $\mathrm{S}$ \\
\hline 16 & AF & 2 & 0 & - & - & 5000 & $\overline{-}$ & GA & A shock & VF & NA \\
\hline 17 & VT & - & - & 8 & 5 & - & 500 & + & - & & $F^{\star}$ \\
\hline 18 & $\begin{array}{l}\text { VF } \\
\text { VT }\end{array}$ & - & - & 0 & 1 & - & 5000 & NA & - & & NA \\
\hline $\begin{array}{l}18 \\
19\end{array}$ & VT & - & - & 3 & 2 & - & 5000 & $++t$ & - & & $\mathbf{F}$ \\
\hline 19 & S VT & - & - & 2 & 0 & - & 250 & +++ & $\bar{v}$ & & $\mathrm{~S}$ \\
\hline 20 & $\{$ VF & - & - & $\begin{array}{l}3 \\
1\end{array}$ & $\begin{array}{l}0 \\
0\end{array}$ & - & $\begin{array}{l}5000 \\
5000\end{array}$ & $\stackrel{+}{\text { NA }}$ & V shock & VF & $\begin{array}{l}\text { F } \\
\text { NA }\end{array}$ \\
\hline 21 & VT & & & 4 & 4 & & & ++ & V shock & $\begin{array}{l}\text { AF } \\
\text { Faster VT }\end{array}$ & $\mathrm{F}$ \\
\hline 21 & VI & - & - & 4 & 4 & - & 5000 & $+t$ & V shock & Faster VI & $\int \mathbf{F}$ \\
\hline 22 & $\{\mathrm{VT}$ & - & - & 10 & 3 & - & 2000 & $+t$ & V shock & VF & $\mathrm{S}$ \\
\hline & UVF & - & - & 3 & 0 & - & 5000 & NA & - & & NA \\
\hline 23 & VT & - & - & 1 & 0 & - & 100 & +++ & - & & $\mathbf{S}$ \\
\hline
\end{tabular}

^Accelerated tachycardia or caused ventricular fibrillation.

A, atrial; AF, atrial fibrillation; AFl, atrial flutter; AVNRT, atrioventricular nodal re-entrant tachycardia; AVRT, atrioventricular re-entrant tachycardia; F, failure; GA, general anaesthetic; NA, not applicable; S, success; V, ventricular; VF, ventricular fibrillation; VT, ventricular tachycardia; + , mild discomfort; ++ , moderate discomfort; +++ , severe discomfort. 
Table 3. Summary of results

\begin{tabular}{|c|c|c|c|c|c|}
\hline \multirow[t]{2}{*}{ Diagnosis } & \multirow[t]{2}{*}{ No of arrhythmias } & \multirow[t]{2}{*}{ No of overall successes } & \multicolumn{2}{|c|}{ No of terminations/attempts (microshock) } & \multirow{2}{*}{$\begin{array}{l}\text { No of terminations } \\
\text { (pacing) }\end{array}$} \\
\hline & & & Atrium & Ventricle & \\
\hline $\begin{array}{l}\text { AFl } \\
\text { AF } \\
\text { AVNRT } \\
\text { AVRT } \\
\text { VT } \\
\text { VF }\end{array}$ & $\begin{array}{r}4 \\
5 \\
3 \\
2 \\
13 \\
3\end{array}$ & $\begin{array}{l}1 \\
0 \\
0 \\
2 \\
8 \\
1\end{array}$ & $\begin{array}{l}0 / 14 \\
0 / 5 \\
0 / 2 \\
5 / 5 \\
- \\
-\end{array}$ & $\begin{array}{c}1 / 3 \\
0 / 9 \\
0 / 9 \\
3 / 3 \\
18 / 59 \\
1 / 5\end{array}$ & $\begin{array}{l}\mathbf{0} \\
\text { NA } \\
3 \\
2 \\
7 \\
\text { NA }\end{array}$ \\
\hline
\end{tabular}

AF, atrial fibrillation; AFl, atrial flutter; AVNRT, atrioventricular nodal re-entrant tachycardia; AVRT, atrioventricular re-entrant tachycardia; NA, not applicable; VF, ventricular fibrillation; VT, ventricular tachycardia.

delivered to the atrium and 88 (4-6700 (mean 945) $\mathrm{mJ}$ ) to the ventricle. Table 2 shows the individual patient data, and Table 3 summarises the results.

\section{ATRIAL FLUTTER}

Atrial flutter was treated in four patients. Shocks were delivered to the atrium in all four patients, a total of 14 times (4-1430 (mean 382) $\mathrm{mJ}$ ) and to the ventricle in one (case 6) only (three shocks of 18,97 , and 198 $\mathrm{mJ})$. There was spontaneous degeneration into atrial fibrillation in two (cases 4 and 5), and one patient would not accept further cardioversion because of pain, which had increased with the use of shocks of increasing energy (case 1). Conversion to sinus rhythm occurred in only one patient (case 6) with a ventricular shock of $18 \mathrm{~mJ}$, but, although this occurred eight complexes after the shock had been delivered, the atrial flutter had been quite stable before this. When flutter was reinduced, however, ventricular shocks of up to $198 \mathrm{~mJ}$ were ineffective, and at one attempt an atrial discharge induced atrial fibrillation which lasted for several minutes before returning to atrial flutter. This arrhythmia eventually reverted to sinus rhythm spontaneously. External cardioversion was needed in one patient during atrial flutter (case 1) and in another after conversion to atrial fibrillation (case 4). Atrial fibrillation, induced in one patient (case 5), reverted to sinus rhythm spontaneously after one hour. Overdrive and extrastimulus pacing were not effective in terminating any of the episodes of atrial flutter, but nor did they provoke atrial fibrillation.

\section{ATRIAL FIBRILLATION}

Atrial fibrillation was treated in five patients. Direct atrial microshock was performed in two patients (case 3 , shocks of 11,130 , and $1390 \mathrm{~mJ}$; case 16 , shocks of 1000 and $5000 \mathrm{~mJ}$ ), but these shocks were all unsuccessful. The other three patients (cases 4,5 , and 7) had previously received atrial discharges for other arrhythmias (atrial fibrillation in these patients occurred spontaneously, from induced atrial flutter, in two, and was induced by microshock, from atrioventricular nodal tachycardia, in one), and further atrial shocks were not given because these previous shocks had caused undue pain. Ventricular shocks were used in four of the patients (nine discharges, 4-3800 (mean 732) $\mathrm{mJ}$ ) but were unsuccessful in terminating these arrhythmias. There was spontaneous reversion in two patients, but three patients (cases 3,4 , and 16) all required external countershock (case 16 after ventricular fibrillation had been induced by a microshock).

\section{JUNCTIONAL TACHYCARDIAS}

Atrioventricular nodal tachycardia-Two of the three patients received atrial and ventricular discharges and one only ventricular shocks. Neither the two atrial (17 $\mathrm{mJ}$ ) nor the nine ventricular (10-500 (mean 118) mJ) shocks caused termination of tachycardia in any of the patients, and a ventricular shock in one patient (case 7) caused atrial fibrillation. Atrial overdrive pacing was effective for terminating tachycardia in all three patients, and although double ventricular extrastimuli were effective for terminating tachycardia in two (cases 9 and 15) atrial extrastimuli were unsuccessful in all three.

Atrioventricular re-entrant tachycardia-Internal cardioversion was effective in both patients with atrioventricular re-entrant tachycardia. The patient in case 6 had five episodes of atrioventricular re-entrant tachycardia induced, and all were terminated using 3.4 and $4.8 \mathrm{~mJ}$ in the right atrium (Fig. 1) and $8.5,15$, and $18 \mathrm{~mJ}$ in the right ventricle. Atrial discharge alone was used in one patient (case 10), and all three episodes of tachycardia were successfully stopped with $20 \mathrm{~mJ}$. Double ventricular extrastimuli were effective for terminating tachycardia in one patient (case 6), and double atrial or ventricular extrastimuli were effective in one (case 10). Overdrive atrial pacing was effective in terminating tachycardia in both patients.

\section{VENTRICULAR TACHYCARDIA}

A total of 59 ventricular shocks (10-6700 (mean 851) $\mathrm{mJ}$ ) was delivered to 13 patients for ventricular tachycardia. Termination by microshock (Fig. 2) was successful in eight patients, five with a superior vena 


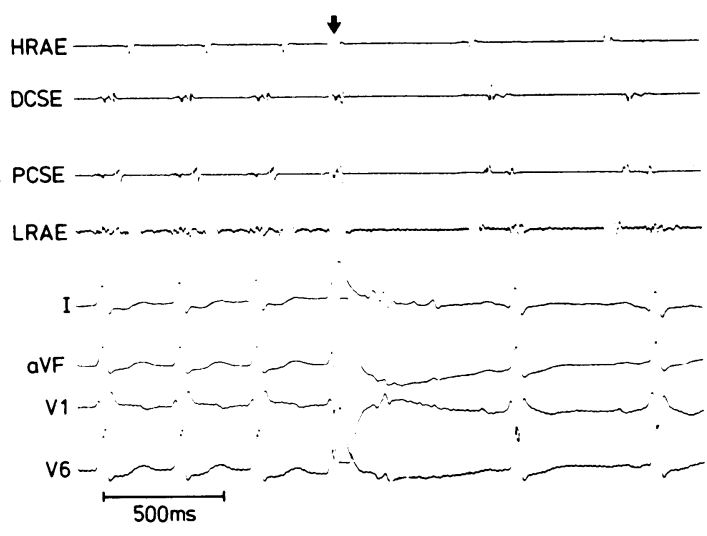

Fig. 1 Electrograms and electrocardiograms showing an atrial shock of $3.4 \mathrm{mf}$ terminating an atrioventricular re-entrant tachycardia due to a left sided accessory pathway (case 6). The arrow indicates the timing of the shock. DCSE, distal coromary sinus electrogram: $H R A E$, high right atrial electrogram; LRAE, low right atrial electrogram; PCSE, proximal coronary sinus electrogram. I, aVF, V1, and V6 are surface electrocardiographic leads.

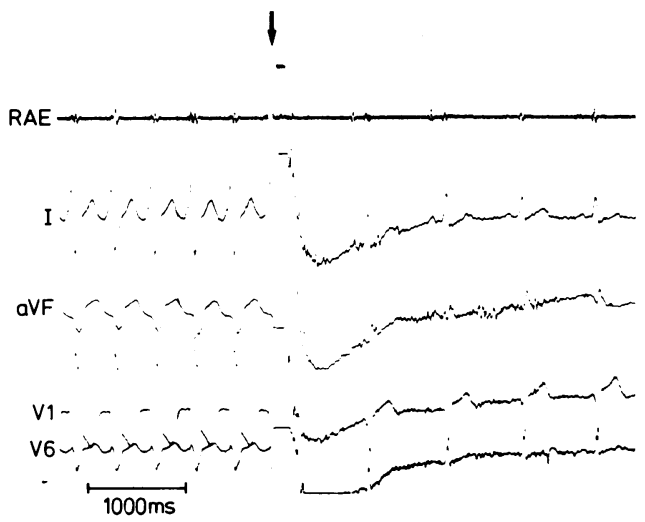

Fig. 2 Electrograms and electrocardiograms showing a right ventricular shock of $150 \mathrm{mf}$ terminating ventricular tachycardia (case 8). The arrow indicates the timing of the discharge. $R A E$, right atrial electrogram. $I, a V F, V 1$, and V6 are surface electrocardiographic leads.

cava-right atrial indifferent and three with an inferior vena cava indifferent electrode. Pacing was attempted in all patients. A single paced extrastimulus was effective in only one patient (case 8) and double stimuli in only two (cases 8 and 13). Overdrive ventricular pacing was effective in seven patients (including cases 8 and 13) but accelerated tachycardia in one and initiated ventricular fibrillation in another; both of these induced arrhythmias were successfully treated with internal microshock.

In some patients subthreshold microshocks (that is, discharges below the threshold energy required for tachycardia termination) could shorten the RR interval of the postshock cycle of tachycardia without terminating it. Nevertheless, the significance of this is unknown.

Of the five patients in whom microshock was ineffective, its further use was limited in three because of pain (case 12, two shocks, maximum $500 \mathrm{~mJ}$; case 19, two shocks, maximum $250 \mathrm{~mJ}$; case 23 , one shock, $100 \mathrm{~mJ}$ ). In the remaining two patients, ventricular fibrillation was induced (case 14, $150 \mathrm{~mJ}$; case 20, $5000 \mathrm{~mJ}$ ), and the study was therefore terminated. Three of these five patients required external countershock (two because of the induced ventricular fibrillation), and two were treated successfully using rapid burst pacing. Three of these five patients had a superior vena cava-atrial indifferent electrode, and two had an inferior cava indifferent.

\section{VENTRICULAR FIBRILLATION}

Ventricular fibrillation was treated by internal microshock in three patients. In one patient (case 17) the arrhythmia was induced by pacing during ventricular tachycardia and immediately responded to a single asynchronous shock of $5000 \mathrm{~mJ}$. In two patients (cases 20 and 22) ventricular fibrillation was induced by microshock (see below), and one and three 5000 $\mathrm{mJ}$ shocks respectively failed to terminate fibrillation. External countershock was effective in both.

\section{ARRHYTHMOGENIC EFFECTS}

Eleven arrhythmogenic effects occurred. Atrial fibrillation, lasting for several minutes, was produced from atrial flutter in one patient (case 6) using $94 \mathrm{~mJ}$ in the right atrium, from atrioventricular nodal tachycardia in one (case 7) using $83 \mathrm{~mJ}$ in the right ventricle, and from ventricular tachycardia in one (case 21) using $1000 \mathrm{~mJ}$ delivered to the right ventricle (Fig. 3). In this latter patient, there was a faster ventricular rate in atrial fibrillation than during ventricular tachycardia.

$\downarrow$

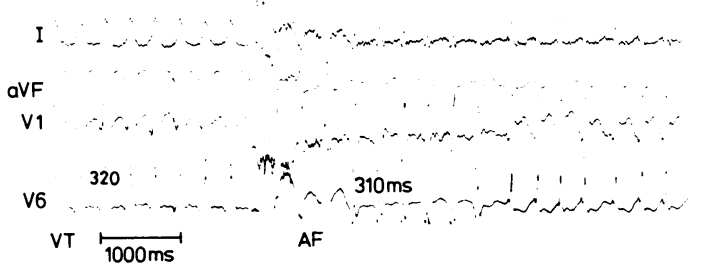

Fig. 3 Electrocardiograms showing a right ventricular shock of $1000 \mathrm{mf}$ terminating ventricular tachycardia (VT) but initiating atrial fibrillation $(A F)$ with two different morphologies of $Q R S$ complex (case 21). The cycle length of the atrial fibrillation is slightly shorter than that of the ventricular tachycardia. The arrow indicates the timing of the discharge. I, aVF, V1, and V6 are surface leads. 
The atrial fibrillation eventually terminated spontaneously. Non-sustained ventricular tachycardia (eight complexes) was induced from atrial fibrillation in the patient in case 7 after a poorly synchronised ventricular discharge of $170 \mathrm{~mJ}$. Ventricular tachycardia was accelerated in two patients, and fibrillation was induced in five. In one patient (case 13), using the externally synchronised system, tachycardia cycle length decreased from 335 to $265 \mathrm{~ms}$ for $4 \mathrm{~s}$ with an apparently well timed discharge of $2700 \mathrm{~ms}$, and in the patient in case 21 , using the internally triggered device, a shock of $500 \mathrm{~mJ}$ accelerated tachycardia from a cycle length of 260 to $215 \mathrm{~ms}$, but this was terminated with a further microshock after $13 \mathrm{~s}$. Ventricular fibrillation was induced from ventricular tachycardia by a poorly timed, externally triggered shock of $150 \mathrm{~mJ}$ in the patient in case 14, which was delivered in the $T$ wave rather than in the QRS complex. In one patient (case 16) an asynchronous atrial shock of $5000 \mathrm{~mJ}$, given for atrial fibrillation, occurred simultaneously with the early part of the QRS complex but nevertheless induced ventricular fibrillation (Fig. 4). In three patients, apparently appropriately timed ventricular shocks for ventricular tachycardia all caused ventricular fibrillation (cases 20 and 21, $5000 \mathrm{~mJ}$; case 22, $500 \mathrm{~mJ}$ ). All these episodes then responded to external defibrillation.

\section{PAIN}

If the pacing test pulse produced pain or diaphragmatic stimulation, the lead was moved to a different site where such pain did not occur. Nevertheless, some patients experienced discomfort during the microshocks. One patient did not complain of any pain or

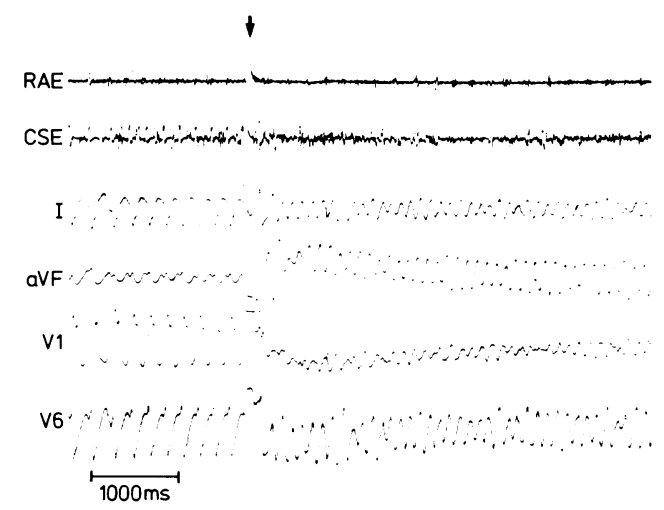

Fig. 4 Electrograms and electrocardiograms showing an asynchronous right atrial shock of $5000 \mathrm{mf}$, delivered using the Medtronic device, for atrial fibrillation (case 16). Although the timing of this shock (see arrow) happens to be synchronous with the onset of the $Q R S$ complex, ventricularfibrillation is induced. $C S E$, coronary sinus electrogram; $R A E$, right atrial electrogram. $I, a V F, V 1$, and V6 are surface electrocardiographic leads. discomfort $(20 \mathrm{~mJ})$, but three complained of mild discomfort (maximum energy, 200-5000 mJ), four of moderate discomfort $(1300-6700 \mathrm{~mJ})$, and 14 of severe discomfort (100-5000 mJ). Pain was not assessed in one patient because a general anaesthetic was used for both the microshocks administered. There was undoubtedly more pain caused by atrial discharges, and discomfort was generally related to the energy delivered in any particular patient. As previously noted, two patients had to be sedated with intravenous diazepam, and two were anaesthetised (one electively and one after unsuccessful lower energy shocks). Patients described shocks of only 4-94 $\mathrm{mJ}$ as severely painful when delivered to the atrium and of $100-5000 \mathrm{~mJ}$ as severely painful in the ventricle. The patients described the pain as "a giant hiccup," "like electrocution," or "like being kicked by a mule," and most of the patients who described severe discomfort declined to have the procedure repeated.

\section{Discussion}

Electrical treatment for arrhythmias has been used both as an adjunct to and as an alternative to drug treatment. Pacemakers typically deliver an energy of approximately $25 \mu \mathrm{J}$ to stimulate the heart. Pacing is not the ideal treatment for many patients with ventricular tachycardia' ${ }^{10} 11$ and is of course of no use in ventricular fibrillation. Pacing is of only very limited value in the treatment of atrial flutter ${ }^{12}$ and has no place as treatment to revert paroxysmal atrial fibrillation. In addition, a small minority of patients with other atrial or junctional tachycardias cannot be adequately treated by pacing. ${ }^{13} 14$

Jackman and Zipes, initially describing their findings in dogs, ${ }^{78}$ suggested that low energy shocks (up to $2500 \mathrm{~mJ}$ ), when delivered through intracardiac electrodes might be effective in treating ventricular tachycardia, and this provided the impetus for the present study of microshock in a wide range of arrhythmias. The results with this technique have been variable. In the present study there were no responders in the group with atrial fibrillation, and only one patient with atrial flutter was successfully treated. The active electrode was frequently positioned on the right atrial septum, which might be thought to be an ideal position, and in addition in one patient (case 1) the lateral right atrial wall was used without success. Even when large epicardial paddle electrodes are used, which might be expected to be effective using lower energies than with relatively small endocardial electrodes, ${ }^{8}$ energies of $10 \mathrm{~J}$ are frequently needed for the treatment of atrial fibrillation occurring during open heart surgery, and this may explain the lack of success with smaller energies deli- 
vered from smaller endocardial electrodes. In the patients with atrial arrhythmias synchronisation of the shock to the atria might have been more effective in terminating the arrhythmia, and also less likely to cause atrial arrhythmias, than a shock synchronised to the ventricles. Even with an atrial electrode, however, some energy will be delivered to the ventricles, and indeed in the present series ventricular fibrillation was induced in one patient by an atrial shock.

The lack of response of the three patients with atrioventricular nodal tachycardia is difficult to understand, but both patients with atrioventricular re-entrant tachycardia responded to very low energy shocks $(3.4 \mathrm{~mJ}$ in case 6 and $20 \mathrm{~mJ}$ in case 10$)$. There is a grey area between a low energy shock and a single paced extrastimulus, and the mechanism of action of a low energy shock may in some cases be analogous to that of a single paced stimulus. In this series, however, single extrastimuli were not effective, from the pacing sites used, in any of the patients with atrioventricular nodal or atrioventricular tachycardias.

Internal cardioversion was successful in eight of 13 patients with ventricular tachycardia, although the energy used was severely limited by pain in three patients, and further attempts were abandoned in two because of the induction of ventricular fibrillation. Pacing was effective in four patients in whom microshock was effective and in three of five in whom it was not; thus only two patients were unresponsive to either pacing or low energy cardioversion.

Considerable discomfort, caused by microshock, was reported by many patients. A total of 14 of the 23 patients experienced severe pain after at least one shock during the evaluation, but pain was never reported after pacing. Cineradiographs recorded during several of the microshocks showed diaphragmatic stimulation in some patients, and the description of a giant hiccup, suggested by many, seems appropriate.

Of even more importance, however, were the arrhythmogenic effects. The development of atrial fibrillation from atrial flutter with an atrial microshock is not particularly sinister nor is the development of atrial fibrillation from atrioventricular nodal tachycardia, even when ventricular shocks are used. Nevertheless, in the presence of an accessory atrioventricular pathway capable of frequent conduction the development of atrial arrhythmias may be serious, and as can be seen from Fig. 3 the development of atrial fibrillation from ventricular tachycardia may lead to an even faster ventricular rate. Nonsustained ventricular tachycardia after ventricular microshock for atrial fibrillation gives rise to concern as does the induction of ventricular fibrillation, using only $150 \mathrm{~mJ}$ in a young patient with otherwise stable ventricular tachycardia. These last two arrhythmias were associated with technical problems causing a lack of synchronisation, with the shock being delivered on the peak of the $T$ wave. Other ventricular arrhythmogenic effects occurred, however, at a time when sensing was technically correct, leading to the apparently well timed delivery of shocks. Sensing may be difficult during rapid arrhythmias, as in the ventricular tachycardia in the patient in case 14 , particularly when sensing from a rather sinusoidal surface QRS complex. Even when sensing from an endocardial electrogram, Jackman and Zipes noted, in their canine work, a higher incidence of arrhythmia degeneration with ventricular tachycardia occurring at a cycle length shorter than $200 \mathrm{~ms}^{8}{ }^{8}$ In addition, sensing problems due to electrode-myocardial interface disturbances are not rare in patients with implantable electrodes used in conjunction with permanent pacemakers, and occasional cases of malsensing will occur with an implantable microshock system for the same reasons, giving rise to potentially disastrous results.

There are several other published studies of the use of internal microshock in man. All used a similar electrode with a variety of external devices. Zipes et al, using a cardioverter delivering a truncated exponential pulse, described successful cardioversion in five of seven patients (all receiving antiarrhythmic drugs), although ventricular flutter was induced in one patient. ${ }^{9}$ It was noted that shocks exceeding $500 \mathrm{~mJ}$ were poorly tolerated. Yee $e t$ al, working in collaboration with Zipes, studied eight patients using damped sinusoidal discharges delivered from a commercial defibrillator with an attenuator. ${ }^{15}$ Eighty six of 99 (87\%) attempts (in six of the eight patients) at terminating 91 episodes of ventricular tachycardia were successful ( $95 \%$ of all episodes were terminated). Three episodes of ventricular flutter were successfully treated as were four of six episodes of ventricular fibrillation (using $5 \mathrm{~J}$ in one case and $40 \mathrm{~J}$ in the others). Waspe et al described 13 patients treated for ventricular arrhythmias. ${ }^{16}$ Only 31 of 50 episodes of ventricular tachycardia were terminated using 160 low energy shocks ranging from 10 to $5000 \mathrm{~mJ}$. There was acceleration of tachycardia or degeneration into ventricular fibrillation during seven episodes of tachycardia using synchronous discharges of 250 to $5000 \mathrm{~mJ}$. Several of the patients experienced severe discomfort, especially with shocks exceeding $500 \mathrm{~mJ}$.

Heilman $e a^{17}$ and Jackman and Zipes ${ }^{8}$ showed that energy requirements for cardioversion or defibrillation may be drastically reduced (up to 250 -fold) by the use of high surface area epicardial electrodes compared with endocardial electrodes. Nevertheless, even when large surface area epicardial electrodes are used for ventricular fibrillation occurring during thoracic surgery, energy requirements may be as high as 2-30 $\mathrm{J},{ }^{18}$ and therefore energies in excess of this may be 
needed when pacing electrodes are used. In studies with the implantable defibrillator, Mirowski et al changed from using a endocardial electrode in canine and short term human work ${ }^{19} 20$ to an epicardial system in conjunction with a transvenous indifferent electrode for human implants, even though this method requires more substantial surgery. ${ }^{34}$

Because of both the considerable discomfort that may occur and its possible dangers, the use of internal microshock is likely to be restricted to those with serious refractory ventricular arrhythmias. The present concept is suitable for short term use in a coronary care unit or electrophysiology laboratory in selected patients, but the lack of backup defibrillation capabilities limits is application for long term implantation. Nevertheless, there are patients who may be refractory to other treatments in whom an implantable device for delivering internal microshocks would be appropriate.

Patients with ventricular tachycardia, in particular, present a difficult therapeutic challenge, and the ideal implantable device may consist of a bradycardia support pacemaker together with a tiered arrangement of antitachycardia pacing, microshock, and defibrillation.

AWN, RSB, and AJC are supported by the British Heart Foundation.

\section{References}

1 Lown B. Electrical reversion of cardiac arrhythmias. $\mathrm{Br}$ Hean f 1967; 29: 469-89.

2 Mirowski M, Mower MM, Staewen WS, Tabatznik B, Mendeloff AI. Standby automatic defibrillator: an approach to prevention of sudden coronary death. Arch Intern Med 1970; 126: 158-61.

3 Mirowski M, Reid PR, Mower MM, et al. Termination of malignant ventricular arrhythmias with an implanted automatic defibrillator in human beings. $N$ Engl $\mathcal{F}$ Med 1980; 303: 322-4.

4 Mirowski M, Mower MM, Reid PR, Watkins L, Langer A. The automatic implantable defibrillator: new modality for treatment of life-threatening ventricular arrhythmias. PACE 1982; 5: 384-401.

5 Reid PR, Mirowski M, Mower MM, Griffith LSC, Platia E, Watkins L. Treatment of ventricular tachycardias with an R-wave synchronized automatic implantable defibrillator [Abstract]. Circulation 1982; 62 (suppl II): 216.

6 Winkle RA. The implantable defibrillator in ventricular arrhythmias. Hosp Pract 1983; 18: 149-65.
7 Jackman WM, Zipes DP. Transvenous, low energy cardioversion of ventricular tachycardia in a canine model of subacute myocardial infarction [Abstract]. Circulation 1981; 64 (suppl IV): 171.

8 Jackman WM, Zipes DP. Low-energy synchronous cardioversion of ventricular tachycardia using a catheter electrode in a canine model of subacute myocardial infarction. Circulation 1982; 66: 187-95.

9 Zipes DP, Jackman WM, Heger JJ, et al. Clinical transvenous cardioversion of recurrent life-threatening ventricular tachyarrhythmias: low energy synchronized cardioversion of ventricular tachycardia and termination of ventricular fibrillation in patients using a catheter electrode. Am Heart f 1982; 103: 789-94.

10 Roy D, Waxman HL, Buxton AE, et al. Termination of ventricular tachycardia: role of tachycardia cycle length. Am $\mathcal{F}$ Cardiol 1982; 50: 1346-50.

11 Naccarelli GV, Zipes DP, Rahilly GT, Heger JJ, Prystowsky EN. Influence of tachycardia cycle length and antiarrhythmic drugs on pacing termination and acceleration of ventricular tachycardia. Am Heart $\mathcal{f}$ 1983; 105: $1-5$.

12 Rosen KM, Sinno MZ, Gunnar RM, Rahimtoola SH. Failure of rapid atrial pacing in the conversion of atrial flutter. Am F Cardiol 1972; 29: 524-8.

13 Peters RW, Shafton E, Frank S, Thomas AN, Scheinman MM. Radiofrequency-triggered pacemakers: uses and limitations: a long-term study. Ann Intern Med 1978; 88: 17-22.

14 Ward DE, Camm AJ, Spurrell RAJ. The response of regular re-entrant supraventricular tachycardia to right heart stimulation. PACE 1979; 2: 586-95.

15 Yee R, Zipes DP, Gulamhusein S, Kallok MJ, Klein GJ. Low energy countershock using an intravascular catheter in an acute cardiac care setting. Am $\mathcal{f}$ Cardiol 1982; 50: 1124-9.

16 Waspe LE, Kim SG, Matos JA, Fisher JD. Role of a catheter lead system for transvenous countershock and pacing during electrophysiologic tests: an assessment of the usefulness of catheter shocks for terminating ventricular tachyarrhythmias. Am $\mathcal{F}$ Cardiol 1983; 52: 47784.

17 Heilman MS, Langer A, Mower MM, Mirowski M. Analysis of four implantable electrode systems for automatic defibrillator [Abstract]. Circulation 1975; 52 (suppl II): 194.

18 Sellers TD, Lake CL, Crampton RS, et al. Energy, current and resistance for direct ventricular defibrillation in man [Abstract]. Am f Cardiol 1982; 49: 1013.

19 Mirowski M, Mower MM, Staewen WS, Denniston RH, Mendeloff AI. The development of the transvenous automatic defibrillator. Arch Intern Med 1972; 129: 773 9.

20 Mirowski M, Mower MM, Gott VL, Brawley RK. Feasibility and effectiveness of low-energy catheter defibrillation in man. Circulation 1973; 47: 79-85. 